\title{
Two new species of Protocirrineris (Polychaeta: Cirratulidae) from Brazil
}

\author{
Rodolfo Elías ${ }^{1}$, María A. Saracho-Bottero ${ }^{1} \&$ Wagner F. Magalhães ${ }^{2}$ \\ 1. Instituto de Investigaciones Marinas y Costeras (IIMyC) - Departamento de Ciencias Marinas, Universidad Nacional \\ de Mar del Plata. Dean Funes 3350, B7602 AYL, Mar del Plata, Argentina, roelias@mdp.edu.ar, \\ asaracho@mdp.edu.ar \\ 2. Water Resources Research Center, University of Hawaii at Manoa, Honolulu, Hawaii, USA, wagnerfm@hawaii.edu
}

$$
\text { Received 15-XI-2018. C Corrected 06-II-2019. Accepted 30-VI-2019. }
$$

\begin{abstract}
Introduction: Brazil has more than $8000 \mathrm{~km}$ of coastline but its marine invertebrates are still poorly known. The cirratulid polychaetes have been an especially neglected group because of its challenging taxonomy. Objective: to describe a new species of Protocirrineris. Methods: In a recent survey in two of the largest Brazilian bays, Todos os Santos Bay and Camamu Bay, 84 specimens of four morphotypes of the multitentaculate genus Protocirrineris were collected. Because of the lack of modified chaetae, the taxonomy of Protocirrineris is challenging and only two of these morphotypes are herein described as new species. Results: These two new species are characterized by having tentacular filaments in two groups over chaetigers 3-4 and first branchiae present from chaetiger 1 . They differ from each other in relation to the nature of the achaetigerous region, posterior region, ultrastructure of capillary chaetae and methyl green staining pattern. Two incomplete specimens are also considered as Protocirrineris, and brief descriptions are given. Conclusions: The genus Protocirrineris is cited for the first time in Brazil. Four new morphotypes were found in two large estuaries of Brazil, and two new species are formally described.
\end{abstract}

Key words: Taxonomy, Protocirrineris, new species, Todos os Santos Bay, Camamu Bay, Northern Brazil.

Elías, R., Saracho-Bottero, M. A., \& Magalhães, W. F. (2019) Two new species of Protocirrineris (Polychaeta: Cirratulidae) from Brazil. Revista de Biología Tropical, 67(S5) Suplemento, S81-S91.

Brazil has a coastline of more than 8000 $\mathrm{km}$ and an extensive continental shelf. Although the country has a large number of groups studying polychaetes (Lana Da Cunha et al., 2017) some families are still under-represented and in need of taxonomic revisions. One of these families is the Cirratulidae Ryckholt, 1851, in which most reported species in Brazil represent widely distributed taxa with low taxonomic certainty. There is a general consensus that the diversity of cirratulids is largely unknown and underestimated and the largely used "cosmopolitan" names are being erroneously applied to local species (Tewary, 2015; Hutchings \&
Kupriyanova, 2018; Elías, Saracho-Bottero, \& Simon, 2019 in this volume).

The first revision of the multitentaculate cirratulids in Brazil applying recent taxonomic standards was by Magalhães, Seixas, Paiva, \& Elias (2014), who recognized seven species and a species complex. The two species widely reported in the Brazilian grey literature, Timarete filigera (Delle Chiaje, 1828) and Timarete tentaculata (Montagu, 1808), were found to be absent in shallow waters along the Brazilian coast and probably have distributions limited to their type localities in the Mediterranean and North Atlantic, respectively (Magalhães et al., 
2014). Other species include the species complex Timarete punctata (Grube, 1859) that was revealed to be composed of two distinct species based on molecular data (Seixas, Zanol, Magalhães, \& Paiva, 2017), T. oculata (Treadwell, 1932), T. caribous (Grube, 1859) and T. ceciliae Magalhães, Seixas, Paiva, \& Elias, 2014 together with Cirriformia chicoi Magalhães et al., 2014 and C. capixabensis Magalhães et al., 2014. The genus Protocirrineris Czerniavsky, 1881 has not been recorded in Brazil up until now.

In recent surveys carried out in Todos os Santos Bay $\left(12.8^{\circ} \mathrm{S}-38.7^{\circ} \mathrm{W}\right)$ and Camamu Bay $\left(13.9^{\circ} \mathrm{S}-39^{\circ} \mathrm{W}\right)$ in northeastern Brazil, four morphotypes of multitentaculate cirratulids lacking specialized spines have been identified as Protocirrineris. The material turned out to be composed of two undescribed species described herein as Protocirrineris baiana sp. nov. and Protocirrineris camamuensis sp. nov. Two additional morphologically distinct species were not formally named because only incomplete specimens were collected. All the diagnostic characters of Protocirrineris species are summarized (Table 1).

\section{MATERIAL AND METHODS}

Eighty-four specimens of multitentaculate cirratulids were collected at the lower and median estuarine region of Paraguaçu estuary, Todos os Santos Bay, northern Brazil (Magalhães \& Barros, 2011). These samples were collected with a $0.3 \mathrm{~m}^{2}$ van Veen grab, washed in the field with sea water through a $0.5 \mathrm{~mm}$ mesh, preserved with $70 \%$ ethanol (see Barros et al., 2008 and Magalhães \& Barros, 2011 for more details). Additional cirratulid specimens came from a collection in subtidal areas at Camamu Bay, in shallow estuarine habitats (Hatje et al., 2008; Pedreira, Barros, Farias, Wagener, \& Hatje, 2017).

All specimens were examined under a dissecting scope, stereomicroscope, and light microscope while selected individuals were observed under a Scanning Electron Microscope (SEM). Material was processed by a
JEOL, JSM-6460 LV scanning electron microscope in the Mar del Plata National University. The material for SEM was prepared performing dehydration in ethyl alcohol (70, 80, 90, 95 and $100 \%$ ). Samples were dried in HMDS (hexamethyldisilazane), mounted on aluminum stubs and sputter coated with Gold Palladium. Type and voucher specimens are deposited at the Museu de Zoologia da Universidade de São Paulo, São Paulo (MZUSP), Brazil. Zoobank link: LSIDurn:lsid:zoobank. org:pub:E03A2C2E-4102-4941-A2EF50CD49742771

\section{RESULTS}

Family Cirratulidae Ryckholt, 1851

Genus Protocirrineris Czerniavsky, 1881

Type Species: Cirratulus tenuisetis Grube, 1860, designated by Hartman (1959)

Diagnosis (after Blake, 1996; Blake \& Magalhães, 2017): Prostomium bluntly conical to wedge-shaped, with or without eyespots. Body nearly round in cross section, with distinct segments. Grooved tentacular filaments few, arising singly or in paired groups on several anterior chaetigers following chaetiger 1; individual tentacular filaments often arranged in longitudinal rows. Branchiae occurring singly, usually first present from segments with tentacular filaments, sometimes on more anterior chaetigers. Chaetae all capillaries. Pygidium a simple lobe.

\section{Protocirrineris baiana sp. nov.}

Fig. 1 A-D

Material examined: Northern Brazil, Todos os Santos Bay, Paraguaçu estuary, Station 1, $12^{\circ} 50^{\prime} 10.5^{\prime \prime} \mathrm{S}, 38^{\circ} 48^{\prime} 04.8^{\prime}$ 'W, May 2005, $16 \mathrm{~m}$ depth, two incomplete specimens of 36 and 38 chaetigers; two complete specimens, Holotype: a complete specimen, 23 $\mathrm{mm}$ long and $0.25 \mathrm{~mm}$ wide for 123 chaetigers (MZUSP 3602); Paratypes: one complete specimen, $19 \mathrm{~mm}$ long and $0.2 \mathrm{~mm}$ width anteriorly and $0.1 \mathrm{~mm}$ width posteriorly for 136 

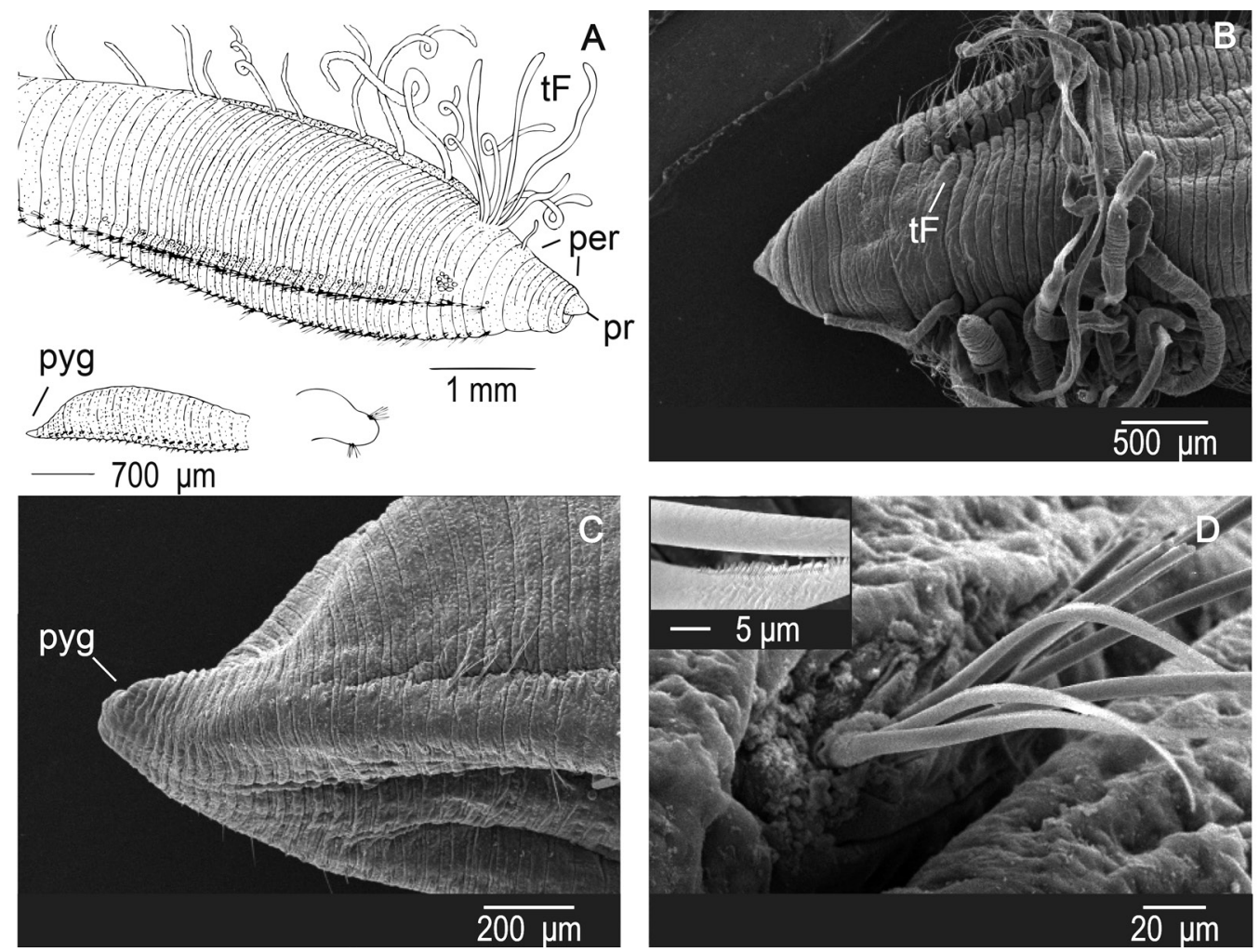

Fig. 1. Protocirrineris baiana sp. nov. A: General view, anterior region. B: Anterior region; C: Posterior region and pygidium; D: Capillary chaetae.

chaetigers (MZUSP 3603). Todos os Santos Bay, Paraguaçu estuary, Sta. 1, 1250'10.5” S, 3848'04.8' W, December 2005, 16 m depth, two incomplete specimens.

Additional material: several fragmented specimens from the same locality and date for Scanning Electronic Microscope.

Description: Holotype complete, $23 \mathrm{~mm}$ long, $0.25 \mathrm{~mm}$ wide for 123 chaetigers. Body in cross section more or less quadrangular anteriorly, inflated dorsally and grooved ventrally. Anterior region laterally expanded with shoulders. Dorsal crest from chaetiger 5 on crowded body segments. Posterior region with a ventral groove, dorsally and laterally expanded; abruptly tapering to simple pygidium and terminal anus (Fig. 1A, C). Color in alcohol pale tan, with pink or orange specks. Tentacular cirri and branchiae paler than body.
Prostomium very short, conical, tucked under peristomium; eyespots absent; nuchal organs not observed. Peristomium triannulated, with 3-4 sub annulations in each annulus. First four chaetigers as long as peristomium also with a sub-annulation. Tentacular filaments from chaetigers 3-4 in two groups of about 5-6 filaments each; branchiae from chaetiger 1, right above notopodia and present throughout (Fig. 1A, B).

Noto- and neuropodia well-separated anteriorly; in first 12-20 chaetigers, notopodium more dorsal then becoming more lateral. Neuropodia ventrally positioned throughout. Capillary chaetae short, about 12-15 notopodial capillaries and 8-10 neuropodial capillaries in anterior segments. Posterior segments bearing five notochaetae and two neurochaetae. Capillaries with a golden reflection, ending in flat 
blade; one side of blade denticulate under SEM (Fig. 1D).

Methyl Green Staining Pattern: branchiae, tentacular filaments and ventrum stained intense blue; prostomium and peristomium stained pale blue.

Habitat: This species was collected in shallow subtidal regions $(16 \mathrm{~m})$ from estuarine environments with variable salinities (30-33) and sediments composed of predominantly coarse sand and granules (see Barros et al., 2008).

Etymology: The name is referred to the type locality, Baía de Todos os Santos (Todos os Santos Bay), and 'baiana' refers to those born in the Bahia state in which this Bay is located.

Remarks: The achaetigerous region of Protocirrineris baiana sp. nov. is very distinct from other species of the genus by having a conical anterior region, with a short prostomium retracted into the peristomium. The peristomium has three distinct annuli each with 3-4 sub annulation being readily distinct from the peristomium of $P$. camamuensis sp. nov., which is shorter, triannulated but lacks distinctive sub-annulations.

The four anterior chaetigers are as long as the peristomium and they have secondary annulations. The first pair of branchiae is anterior to the tentacular filaments arising from chaetiger 1 . Only two other species have branchiae originating before the tentacular filaments: P. socialis Blake, 1996 from California and P. magalhaesi Elías et al., 2019 from South Africa. The tentacular filaments of P. baiana sp. nov. are not organized into rows but in two groups of 5-6 filaments each. The posterior region of the new species is inflated, only comparable with $P$. magalhaesi, but the anus is terminal, while in the South African species it is dorsal. Capillary chaetae are very short, stout, denticulate in one side of the blade in P. baiana sp. nov. For further comparison see Table 1.

Protocirrineris camamuensis sp. nov.

Fig. 2 A-D
Material examined: Northern Brazil, Camamu Bay, Station 6S2A, 1345'23.9" S, 3904'50.6" W, 3.4 m depth, July 2005, Holotype: a single complete specimen (broken in two parts during staining process), $20 \mathrm{~mm}$ long for 95 chaetigers (MZUSP 3604).

Description: Holotype complete, $20 \mathrm{~mm}$ long for 95 chaetigers; quadrangular in cross section, flattened dorso-ventrally with inflated dorsum and grooved ventrum. Chaetigers crowded throughout. Parapodia forming shoulders after tentacular filaments, reaching maximum width at chaetiger 35 . Posterior region rounded, laterally expanded, ending in a conical section of several crowded chaetigers, with several sub-annulations; pygidium conical with anus terminal. Color in alcohol tan, with whitish branchiae and tentacular filaments.

Prostomium short and wide; barely protruding from peristomium; eyespots absent and nuchal organs not observed. Peristomium short, subequal in length to four anterior chaetigers, with three same-sized annuli. Tentacular filaments short (possibly regenerating) rising from chaetigers 3-4, organized into two groups of 5-6 filaments each. Branchiae from chaetiger 1 , dorsal to notopodium, present to end of the body but sporadically (Fig. 2A).

Noto- and neuropodia widely separated; notopodia lateral and neuropodia ventral. Parapodia forming distinct shoulders posterior to tentacular filaments (Fig. 2B). Capillary chaetae present though out noto- and neuropodia. Capillaries finely denticulated on one side of blade (Fig. 2D). Notopodia with 10-20 capillaries per ramus, neuropodia with $12-15$ capillaries per ramus in anterior region, decreasing in number posteriorly. Parapodial tori slightly projecting from body wall posteriorly and capillaries shorter than anteriorly.

Methyl Green Staining Pattern: Entire body stained with uncolored patches in the ventrum of the peristomium, dorsal region and parapodial shoulders, and the posterior cone where the anus opens.

Remarks: Protocirrineris camamuensis sp. nov. is clearly distinct from all other known Protocirrineris species. The robust body is 


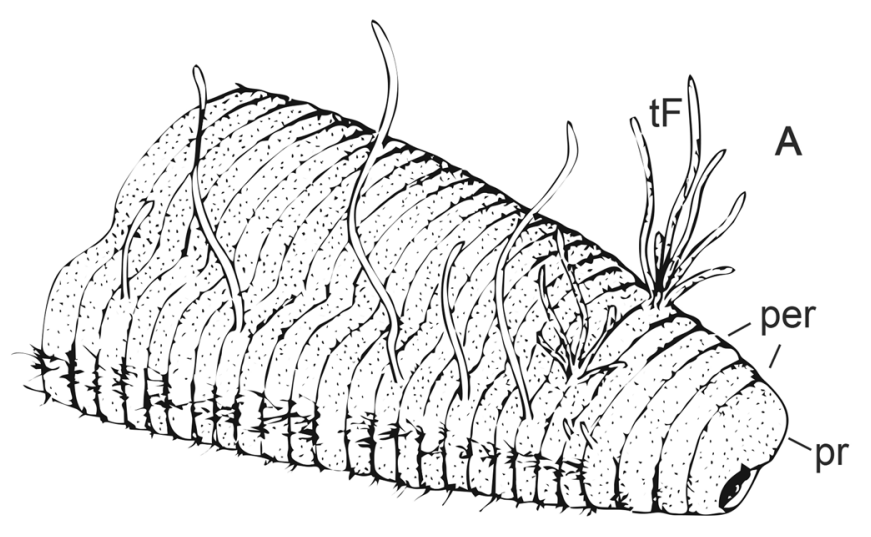

$500 \mu \mathrm{m}$

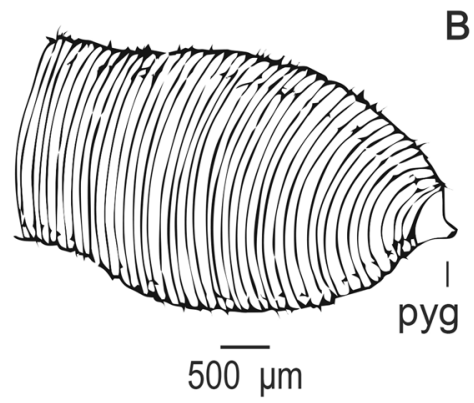

B

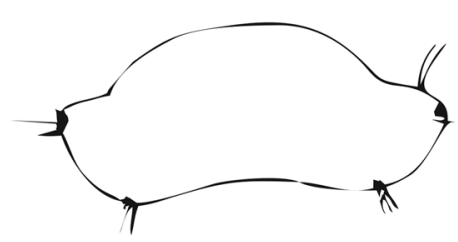

Fig. 2. Protocirrineris camamuensis sp. nov. A: anterior region; B: posterior region and pygidium; C: cross section in thoracic region, showing long and abundant notochaetaes and the ventral neuropodium with short and scares chaetae.

very different from most Protocirrineris species that usually have a slender body. The general shape of the body, flattened and laterally expanded, is an unusual feature in Protocirrineris. The only similarity is with one (out of the two) P. socialis Blake, 1996 morphotypes described by Blake (1996). However, the pattern of tentacular filaments is different in these two species. The presence of branchial filaments from chaetiger 1 is shared with a few species such as $P$. baiana sp. nov., $P$. socialis from California and P. magalhaesi Elías et al., 2019 from South Africa. A short prostomium is present in $P$. baiana sp. nov., although in that species is acute, and in P. camamuensis sp. nov. is rounded and flattened. The posterior region being laterally enlarged and expanded is unique in the genus. The neuropodia are ventral from the first chaetiger to the last similar to in $P$. baiana sp. nov. See also Table 1.
Habitat: This species was collected within Camamu Bay in shallow water estuarine sediments. Sediment in the site is composed of sand $(79.9 \%)$ and silt-clay $(11.1+8.95 \%$, respectively). The site has high values of $\mathrm{Mn}$ and $\mathrm{Fe}$ and is assumed to have lowered the diversity and abundance of the benthic assemblage (Hatje et al., 2008).

Etymology: This species is named after its type locality Camamu Bay.

\section{Protocirrineris sp. A}

Fig. 3 A-D

Material examined: Northern Brazil, Todos os Santos Bay, Paraguaçu estuary, Sta. 1, $12^{\circ} 50^{\prime} 10.5^{\prime}$ S, 38 $48^{\prime} 04.8^{\prime \prime} \mathrm{W}$, December 2005, $16 \mathrm{~m}$ depth, a single incomplete specimen, about $76 \mathrm{~mm}$ long for 85 chaetigers. 


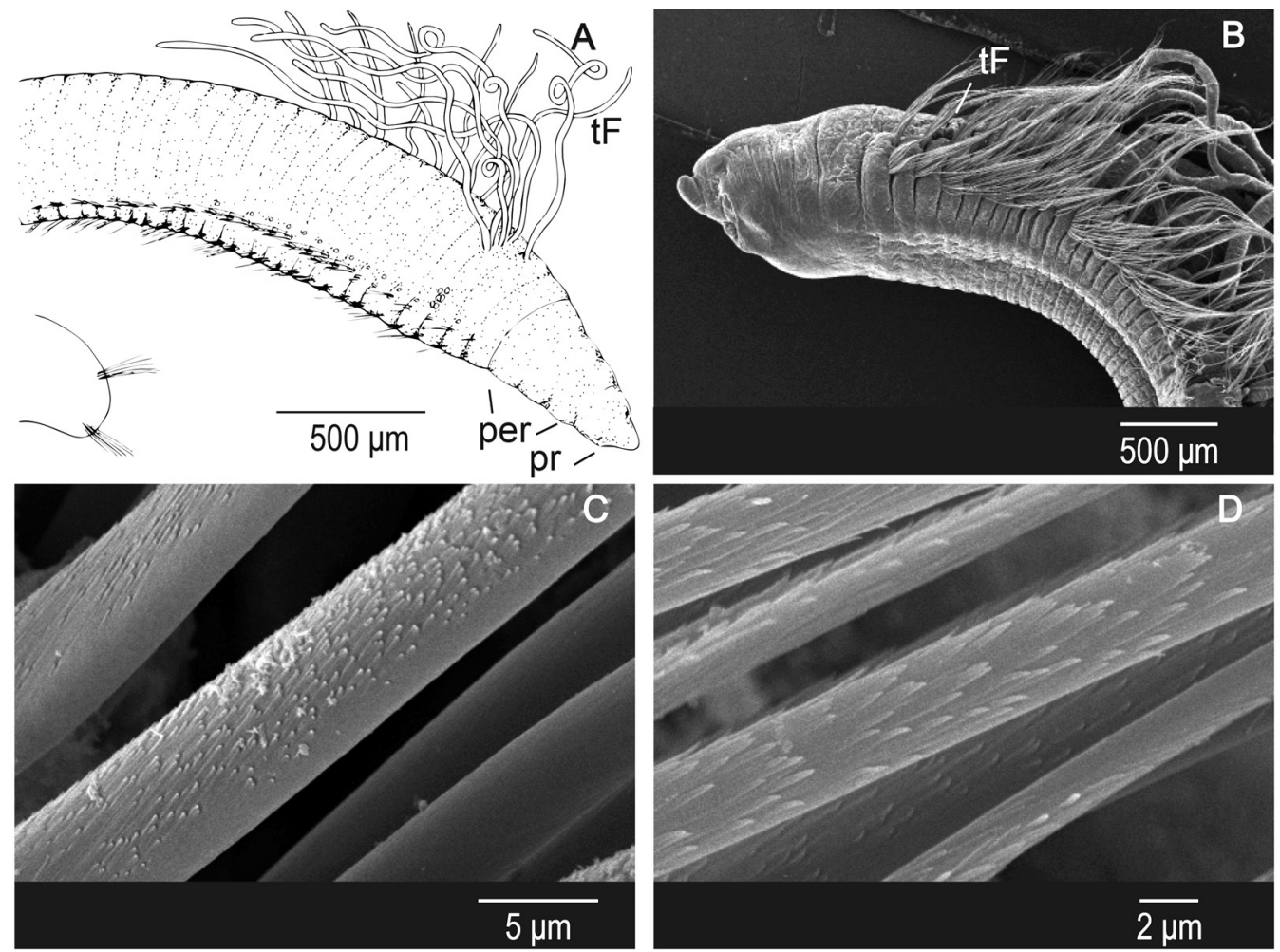

Fig. 3. Protocirrineris sp. A. A: Schematic draws of anterior region and cross section. B: SEM of the anterior region. Note the long and abundant capillaries in both noto- and neuropodium. C: Detail of capillary chaetae stout and finely striate in one edge. D: Detail of capillary chaetaes finely denticulate with small spaced teeth and tip slightly raised, all around its circumference.

Additional material: several incomplete fragments analyzed by SEM.

Description: Examined specimen incomplete; body quadrangular in cross-section anteriorly, dorsally round and ventrally flat with ventral groove. Color pale tan, with iridescent spots, tentacular filaments and branchiae whitish.

Prostomium short, triangular and flattened, with two front-lateral dark spots (eyespots or colored nuchal organs?). Peristomium tri-annulated, as long as first five chaetigers. Tentacular filaments in two groups (6-8 filaments each) between chaetigers 3-4. Branchiae from chaetiger 1 , dorsal to notochaetae and in posterior part of segment.

Noto- and neuropodia separated; separation between noto- and neuropodia becoming wider from chaetigers 6 to 21 , forming distinct shoulders. Neuropodia almost ventral in anterior region. Capillary chaetae present throughout, 15-20 capillaries in notopodia, 10-15 in neuropodia in anterior region, decreasing progressively to end of body. All specimens composed of anterior fragments, posterior end and pygidium not known.

Methyl Green Staining Pattern: No clear pattern of stain was observed.

\section{Protocirrineris sp. B}

Fig. 4 A-D

Material examined: Northern Brazil, Todos os Santos Bay, Paraguaçu estuary, May 2015, Station 1 (3 incomplete specimens), $12^{\circ} 50^{\prime} 10.5^{\prime}$ S S, 38 $48^{\prime} 04.8^{\prime \prime} \mathrm{W}$; December 

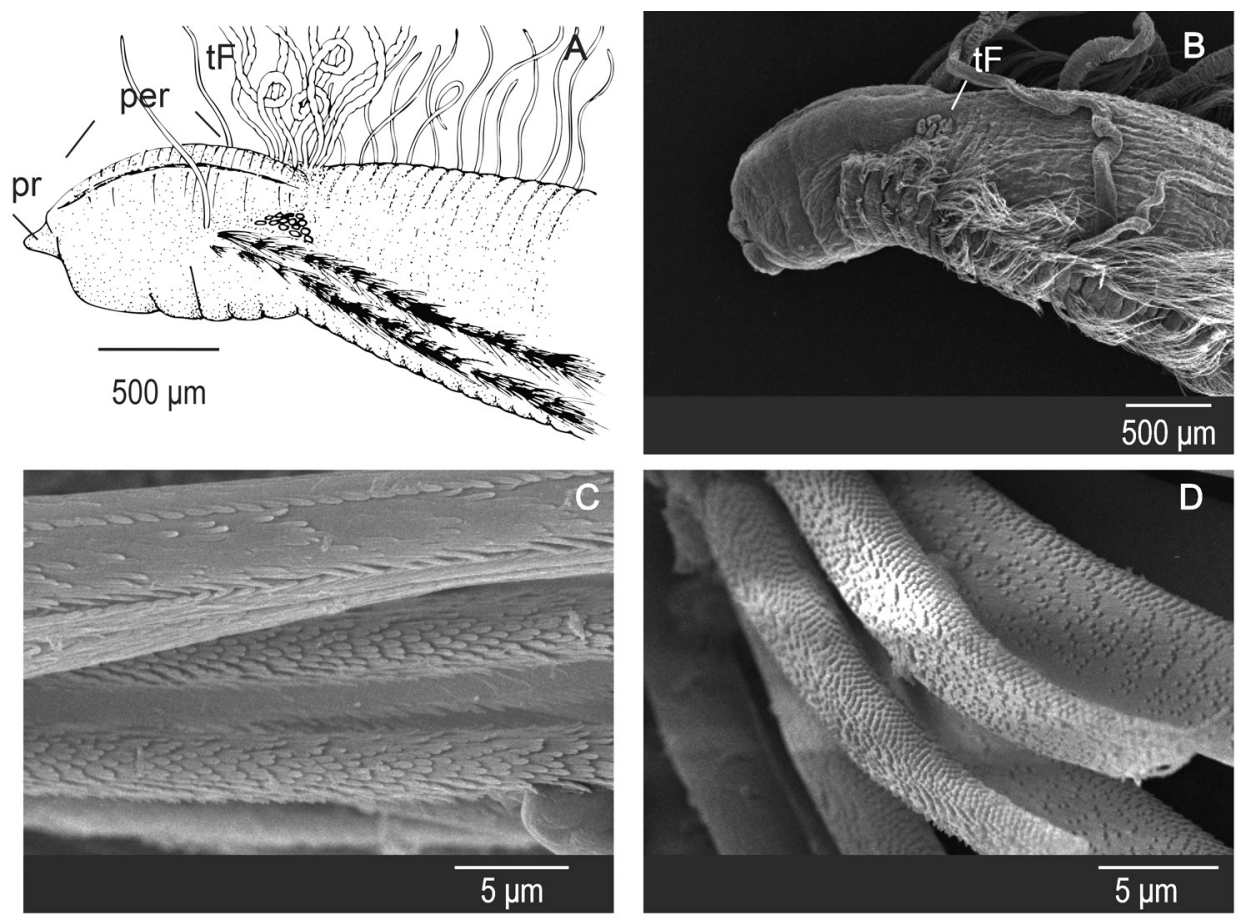

Fig. 4. Protocirrineris sp. B. A: Schematic draw of anterior region. B: SEM of anterior region with long capillary chaetae. $\mathrm{C}$ : Long capillaries denticulate, with numerous and tight teeth, the tip is raised. D: Capillaries with numerous and tight teeth.

2005, 16m depth; Station 5, 1245'50.2" S, $38^{\circ} 52^{\prime} 35.5^{\prime \prime} \mathrm{W}$, three incomplete specimens; December 2005, Station 1, 12 ${ }^{\circ} 50^{\prime} 10.5^{\prime \prime} \mathrm{S}$, $38^{\circ} 48^{\prime} 04.8^{\prime \prime} \mathrm{W}$, a single incomplete specimen $55 \mathrm{~mm}$ long for 63 chaetigers.

Additional material: several fragments analyzed by SEM.

Description: All examined specimens' incomplete posteriorly; longest anterior fragment with 63 chaetigers. Body oval in cross section, dorsally inflated, with a shallow ventral groove anteriorly, more deeply grooved posteriorly; body laterally expanded forming shoulders in anterior region, reaching maximum width in chaetigers 26-33, subsequent chaetigers are not as wide and more crowded. Color in alcohol pale tan.

Prostomium short, conical; eyespots absent; nuchal organs not observed. Peristomium with two annuli best distinguished laterally; dorsal crest present along peristomium, continuing to chaetiger 4 with a shallow central groove. First three chaetigers longer than subsequent ones, as long as peristomium (Fig. 4). Tentacular filaments from chaetigers 2-4 right after crest formed from peristomium; filaments organized in two groups numbering 10-17 filaments in each group. First pair of branchiae on first chaetiger, dorsal to notopodium; subsequent branchiae on same position and branchiae present anteriorly.

Noto- and neuropodia close together, most anterior segments with notopodia almost dorsally placed and close to tentacular filaments, then becoming lateral after chaetigers 4-5. Neuropodia lateral throughout. Notopodia and neuropodia with numerous very long capillaries, longer and more abundant in notopodia, 22-25, and 13-18 in neuropodia anteriorly, decreasing to the middle and posterior region. Capillaries with dense tabs attached and tip raised, some capillaries shorter with blunt denticulations, very dense on one side, more scattered on rest (Fig. 4).

Methyl Green Staining Pattern: Branchiae, tentacular filaments and ventrum stained 
dark blue; prostomium and peristomium stained a paler blue.

Remarks: Protocirrineris sp. B is a very distinct member of the genus by the presence of a dorsal peristomial grooved crest that extends back to chaetiger 4. Capillary chaetae are longer and numerous in comparison to other known Protocirrineris species. The pattern of ornamentation is also quite different from the other congeners. Similarly to other Brazilian species of Protocirrineris, the branchial filaments are first present from chaetiger 1, anterior to tentacular filaments.

Habitat: Specimens were collected at middle and lower regions of Paraguaçu estuary at Stations 1 and 5 with salinities varying from 23-30 and sediments composed of mostly sand and coarse sand (Sta. 1) and fine grained sand (Sta. 5).

\section{DISCUSSION}

Two new species of Protocirrineris are herein described and characterized by the presence of tentacular filaments in two packs between chaetigers 3 and 4 . The other two morphotypes are composed of incomplete specimens but they seem to be adult individuals and to be morphologically distinct from the two new species. The posterior end of the body was missing and there are no references about the presence of spines in the last chaetigers, however the general aspect of the body suggests that they lack spines or any other type of modified chaetae. This is the reason why we identified these worms as belonging to Protocirrineris. The identification and formal description of these morphotypes must await for new, complete material, to confirm the existence of additional new species.

The genus Protocirrineris is present in the southwestern Atlantic ( $P$. angellicolatio Elías \& Rivero, 2009), northeastern Pacific ( $P$. socialis Blake, 1996), northwestern Pacific ( $P$. mascaratus Magalhães \& Bailey-Brock, 2013), France ( $P$. tenuisetis Grube, 1860), southwestern Pacific (P. nuchalis (Ehlers, 1907)), Indic (P. indicus Day, 1973), Mediterranean
(P. chrysoderma (Claparède, 1868) and $P$. purgamentorum Lezzi, Çinar, \& Giangrande, 2016) and South African (P. strandloperarum and P. magalhaesi, Elías et al., 2019). The two species and the two morphotypes described here constitute new additions to the known Protocirrineris species from the coast of Brazil (Table 1). The geographical distribution of most species is restricted to the type locality with the exception of $P$. chrysoderma, which has been reported to be widespread in the Atlantic, Mediterranean and Pacific. Petersen (1991), however, argues that P. chrysoderma may be a complex of species and a closer look at these morphologically similar taxa using SEM imaging could reveal that may be a much more species-rich taxon (Lezzi et al., 2016; Magalhães, 2015). The evidence suggests that Protocirrineris species may be more locally endemic than previously known.

The table provided by Magalhães \& Bailey-Brock (2013) was modified to include the new species and novel morphotypes described herein as well as the new species described in Elías et al. (2019) from South Africa in this same volume (Table 1). We propose a table, with the characters herein described for each new species, to aid in the identification of any new species of Protocirrineris encountered.

The twelve described species of Protocirrineris (the Table does not include the two morphotypes) may be distinguished by the segmental origin and the extent and number of feeding tentacles. Tentacular filaments could be in longitudinal rows or in packs occupying 2-3 anterior chaetigers (see Table 1). The origin of branchiae is usually from the posterior-most tentacle-bearer segments but these are sometimes difficult to see without the aid of SEM, but still are considered a diagnostic character. Here we add two species and two morphotypes with branchiae in anterior chaetigers, plus the existing species (P. socialis). Methyl green staining patterns have been described for four out of the six species but only Protocirrineris mascaratus has a distinctive staining pattern. The description of $P$. tenuisetis is insufficient to confirm its identity and according to Hartman 
(1959) this species should be considered as indeterminate.

The ultrastructure of the capillary fibrils might be a relevant character but it has only been shown for $P$. mascaratus and $P$. angellicolatio and they appear to be distinct in width, shape, and number of fibrils along the capillary chaetal blade (compare Fig. 4.3.2C, D herein to Elías \& Rivero, 2009: Fig. 2E, F). The usefulness of capillary fibrils to cirratulid taxonomy has been discussed for the bitentaculate genus Aphelochaeta (Doner \& Blake 2009; but also see Elías, Rivero, \& Orensanz, 2016) but a unifying terminology is lacking (see Fig. 4, Elías et al. 2019, in this volume).

The phylogenetic relationships within the Cirratulidae have never been investigated in detail. The lack of reliable characters is problematic in the understanding of the phylogeny of this group, as it has been shown that most of the characters used in species level descriptions of multitentaculate cirratulids, i.e. segmental origin of feeding tentacles and acicular spines vary ontogenetically (e.g. Magalhães \& Bailey-Brock, 2010). A related issue is the broad generic diagnoses currently in use. Over the years, the systematic accounts have been modified to include a wider interpretation of what the characteristics of a species included in a particular genus are so that a place could be found for those species that did not seem to fit anywhere. These vague definitions result in species having been placed in a genus more for convenience than to reflect evolutionary relationships (Tewary, 2015).

Biogeographically, the region of study is particularly interesting because two species and an additional two Protocirrineris morphotypes were found in two very close sites on the coast of Brazil. Recently, two species of this genus were described for the coast of South Africa (Elías et al. 2019, in this volume), which was justified by the existence of three biogeographical regions on that coast, although the species of Brazil belong to the same biographical region.
The understanding about the diversity of cirratulid species in Brazil is in its first steps. Additional sampling across different habitats, examination of museum collections on top of examining samples through molecular analysis are needed in order to confirm the identification of widespread and cryptic species.

Ethical statement: authors declare that they all agree with this publication and made significant contributions; that there is no conflict of interest of any kind; and that we followed all pertinent ethical and legal procedures and requirements. All financial sources are fully and clearly stated in the acknowledgements section. A signed document has been filed in the journal archives.

\section{AKNOWLEDGEMENTS}

SEM images were obtained by Mónica Oppedisano from the Laboratorio de Microscopía Electrónica of Facultad de Ciencias Exactas y Naturales of the Universidad Nacional de Mar del Plata. The drawings were made by R.E. Figures composition by M.A.S.B. Two anonymous reviewers improved the manuscript.

\section{RESUMEN}

\section{Dos nuevas especies de Protocirrineris (Polychaeta: Cirratulidae) de Brasil}

Introducción: Brasil tiene más de $8000 \mathrm{~km}$ de costa, pero sus invertebrados marinos aún son poco conocidos. Los poliquetos cirratulidos han sido un grupo especialmente descuidado debido a su desafiante taxonomía. Objetivos: Identificar morfotipos de Cirratulidae multitentaculados y encontrar nuevos caracteres diagnósticos. Métodos: En muestreo reciente en dos de las bahías más grandes de Brasil, Bahía de Todos los Santos y Bahía de Camamu, se colectaron cuatro morfotipos del género multitentaculado Protocirrineris. Resultados: debido a la falta de quetas modificada, la taxonomía de Protocirrineris es un desafío y solo dos de estos morfotipos se describen aquí como nuevas especies. Estas dos nuevas especies se caracterizan por tener filamentos tentaculares en dos grupos sobre los quetígeros 3-4 y las primeras branquias presentes 
de quetígero 1. Se diferencian entre sí en relación con la naturaleza de la región sin quetas, región posterior, ultraestructura de las quetas capilares y el patrón de tinción con verde de metilo. Dos especímenes incompletos también se consideran Protocirrineris, y se dan breves descripciones. Conclusiones: Se cita por primera vez la presencia del género Protocirrineris en Brasil. Cuatro morfotipos del género han sido encontrados en dos grandes estuarios de Brasil. Dos especies nuevas para la ciencia son descriptas.

Palabras clave: Taxonomía, Protocirrineris, especies nuevas, Bahía de Todos los Santos, Bahía de Camamu, Norte del Brasil.

\section{REFERENCES}

Barros, F., Hatje, V., Figueiredo, M. B., Magalhães, W. F., Dores, H. S., \& Emidio, E. S. (2008). The structure of the benthic macrofaunal assemblages and sediments characteristics of the Paraguaçu estuarine system, NE, Brazil. Estuarine, Coastal and Shelf Science, 78, 753-762.

Blake, J. A. (1996). Family Cirratulidae Ryckholdt, 1851. Including a revision of the genera and species from the Eastern North Pacific. In J. A. Blake, B. Hilbig \& P. H. Scott (Eds.). Taxonomic Atlas of the Benthic Fauna of the Santa Maria Basin and Western Santa Barbara Channel, Volume 6. The Annelida Part 3. Polychaeta: Orbiniidae to Cossuridae (pp. 263384). Santa Barbara, California, USA: Santa Barbara Museum of Natural History.

Blake, J. A. \& Magalhães, W. F. (2017). Family Cirratulidae Ryckholt, 1851. In W. Westheide \& G. Purschke (Eds.). Handbook of Zoology, a Natural History of the Phyla of the Animal Kingdom (pp. 1-56). Berlin, Germany: de Gruyter.

Claparède, E. (1868). Les Annélides Chétopodes du Golfe de Naples. Memoires de la Société de physique et d'histoire naturelle de Genève 20(2), 365-542.

Czerniavsky, V. (1881). Materialia Ad Zoographiam Ponticam Comparatam. Fasciculum III. Vermes. Bulletin de la Société Impériale des Naturalistes de Moscou, 55(4), 213-344.

Day, J. H. (1973). Polychaeta collected by U. D. Gaikwad at Ratnagiri, south of Bombay. Zool. J. Limn. Soc., $52,337-361$.

Delle Chiaje, S. (1828). Memorie sulla storia e notomiadegli animali senza vertebre del regno di Napoli. Volume III. Naples, Italy: Società Tipografica.

Doner, S. A., \& Blake, J. A. (2009). Two new species of Aphelochaeta (Polychaeta: Cirratulidae) from deep water off northern California. Zoosymposia, 2, 127-137.
Elías, R., \& Rivero, M. S. (2009). Two new species of Cirratulidae (Polychaeta) from Argentine Sea (SW Atlantic). Zoosymposia, 2, 139-148.

Elías, R., Rivero, M. S., \& Orensanz, J. M. (2016). New species of Monticellina and Chaetozone (Polychaeta: Cirratulidae) in the SW Atlantic, and a Review of Monticellina species. Journal of the Marine Biological Association of the United Kingdom, 97(7), 1553-1563.

Elías, R., Saracho-Bottero, M. A., \& Simon, C. A. (2019). Protocirrineris (Polychaeta:Cirratulidae) in South Africa and the description of two new species. Revista de Biología Tropical, X(X): S000-S000.

Grube, A. E. (1859) Annulata Orstediana. Copenhagen, Denmark: Videnskabelige Meddelelser fra Dansk Naturhistorisk Forening.

Grube, A. E. (1860). Beschreibung neuer oder wenig bekannter Anneliden. Fünfter Beitrag. Archiv für Naturgeschichte, Berlin, 26(1), 71-118.

Hartman, O. (1959). Catalogue of the Polychaetous Annelids of the World. Parts 1 and 2. Allan Hancock Foundation Occasional Paper, 23, 1-628.

Hatje, V., Barros, W. F., Magalhães, W., Riatto, V. B., Amorim, F. N., Figueiredo, M. B., ... Cirano. M. (2008). Trace metals and benthic macrofauna distributions in Camamu Bay, Brazil: Sediment quality prior oil and gas exploration. Marine Pollution Bulletin, 56, 348-379.

Hutchings, P., \& Kupriyanova, E. (2018). Cosmopolitan polychaetes - fact or fiction? Personal and historical perspectives. Invertebrate Systematics, 32, 1-9.

Lana Da Cunha, P., Pagliosa, P., Paiva, P. C., Carrerette, O., Paresque, K., Matos Nogueira, ... Fukuda, M. V. (2017). Polychaetes in Brazil: people and places, past, present and future. In O. Díaz-Díaz, D. Bone, C. T. Rodríguez \& V. H. Delgado-Blas (Eds.). Poliquetos de Sudamérica (pp. 24-50). Cumaná, Venezuela: Volumen especial del Boletín del Instituto Oceanográfico de Venezuela.

Lezzi, M., Çinar, M. E., \& Giangrande, A. (2016). Two new species of Cirratulidae (Annelida: Polychaeta) from the southern coast of Italy. Marine Biodiversity, 46(3), 681-686.

Magalhães, W. F. (2015). Reef and shore Polychaetes of Hawaii and the western Pacific Islands (Doctoral thesis). Hawaii, USA: University of Hawaii.

Magalhães, W. F., \& Bailey-Brock, J. H. (2010). Redescription of Cirriformia crassicollis (Kinberg, 1866) and Timarete hawaiensis (Hartman, 1956) new combination, (Polychaeta: Cirratulidae), endemic polychaetes to the Hawaiian Islands. Zootaxa, 2625, 53-62. 
Magalhães, W. F., \& Barros, F. (2011). Structural and functional approaches to describe polychaete assemblages: ecological implications for estuarine ecosystems. Marine and Freshwater Research, 62, 918-926.

Magalhães, W. F., \& Bailey-Brock, J. H. (2013). A new species of Protocirrineris (Polychaeta: Cirratulidae) from Hawaii including a redescription of the New Zealand Protocirrineris nuchalis. New Zealand Journal of Zoology, 40(3), 196-204.

Magalhães, W. F., Seixas, V. C., Paiva, P. C., \& Elías, R. (2014). The multitentaculate Cirratulidae of the genera Cirriformia and Timarete (Annelida: Polychaeta) from shallow waters of Brazil. PLOS ONE, 9(11), $1-20$.

Montagu, G. (1808). Description of several marine animals found on the south coast of Devonshire. Transactions of the Linnean Society of London, 9, 81-114.

Pedreira, R. M. A., Barros, F., Farias, C. O., Wagener, A. L., \& Hatje, V. (2017). A tropical bay as a reference area defined by multiple lines of evidence. Marine Pollution Bulletin, 123, 291-303.
Petersen, M. E. (1991). A review of asexual reproduction in the Cirratulidae (Annelida: Polychaeta), with redescription of Cirratulus gayheadius (Hartman, 1965), new combination, and emendation or reinstatement of some cirratulid genera. Bulletin of Marine Science, 48,592 .

Ryckholt, P. (1851). Mélanges paléontologiques. Part 1. Memoires Couronneset Memoires des Savants Etrangers de l'Academie Royale des Sciences, des Lettres et des Beaux-Arts de Belgique, 24, 1-176.

Seixas, V. C., Zanol, J., Magalhães, W. F., \& Paiva, P. C. (2017). The genetic diversity pattern of Timarete punctata (Annelida: Cirratulidae) species complex identifies a potential biological invader. Estuarine, Coastal and Shelf Science, 197, 214-220.

Tewary, S. A. (2015). Taxonomy of the Bitentaculate Cirratulidae (Polychaeta) (Master's thesis). Boston, USA: University of Massachusetts Boston.

Treadwell, A. L. (1932). Annelidos polychetos novos da Ilha de Sao Sebastiao. Revista do Museu Paulista, $17(2), 1-20$. 